Article

\title{
Environmental Efficiency Analysis for Multi Plants Production Technologies
}

\author{
Mojtaba Ghiyasi ${ }^{1, *}$ and Farhad Taghizadeh-Hesary ${ }^{2, *(1)}$ \\ 1 Faculty of Industrial Engineering and Management Science, Shahrood University of Technology, \\ Shahrood 3614773955, Iran \\ 2 Social Science Research Institute, Tokai University, 4-1-1 Kitakaname, \\ Hiratsuka-shi 259-1292, Kanagawa, Japan \\ * Correspondence: mog@shahoodut.ac.ir (M.G.); farhad@tsc.u-tokai.ac.jp (F.T.-H.)
}

check for updates

Citation: Ghiyasi, M.;

Taghizadeh-Hesary, F. Environmental Efficiency Analysis for Multi Plants Production Technologies.

Sustainability 2021, 13, 3989.

https://doi.org/10.3390/su13073989

Academic Editor: Enrique

Rosales-Asensio

Received: 24 February 2021

Accepted: 29 March 2021

Published: 2 April 2021

Publisher's Note: MDPI stays neutral with regard to jurisdictional claims in published maps and institutional affiliations.

Copyright: (c) 2021 by the authors. Licensee MDPI, Basel, Switzerland. This article is an open access article distributed under the terms and conditions of the Creative Commons Attribution (CC BY) license (https:// creativecommons.org/licenses/by/ $4.0 /)$.

\begin{abstract}
The current article extends the literature by proposing new models for estimating the classical and environmental performance of multi-plant firms. This yields some new indices for capturing the environmental performance vs. classical economic performance at the local and global level. The proposed approaches and indices were applied for the economic and environmental performance assessment of 46 power plants in Iran. The primary result emphasizes considering not only local environmental performance but also global performance to have a broad insight of environmental performance assessments. Moreover, we find only a few power plants with a resistant environmental performance at the global level. Proposed models in this article are general because they can be utilized in environmental analysis of any multiple plant production units.
\end{abstract}

Keywords: DEA; multi plant firms; environmental assessment; local-global performance

\section{Introduction}

Environmental issues are becoming more important as a consequence of growing pollution-generating technologies. Greenhouse gas emissions reduction is one of the main concerns of all societies in this century. A five percent reduction of greenhouse gas emissions on average was decided in the Kyoto Protocol for 2008-2012 compared with 1990. This reduction level was decided to be 50 percent on average in Copenhagen. Industries are one of the main sources of emissions production in all countries. The reduction path has been decided to be gradual, since cutting down the emissions may be possible because it they are a byproduct in industries. The key factor in emissions reduction is the performance and the efficiency of production technology. Data envelopment analysis (DEA) is a mathematical programming-based approach for efficiency analysis of a group of decision-making units (DMUs) proposed by [1]. In this paper, we propose new models for estimating the classical and environmental performance of multi-plant firms. Then we develop some new indices for capturing the environmental performance vs. classical economic performance at the local and global level. The proposed approach is utilized for the economic and environmental performance assessment of 46 power plants in Iran. The primary result emphasizes considering not only local environmental performance but also global performance to have a broad insight into environmental performance assessments. Primary results show that we have only a few power plants that are resistant to environmental performance at the country level when we use models with non-uniform scaling factors for desirable and undesirable outputs. This is due to the higher discrimination power of associated economic and environmental efficiency measures of these indices. Another important result is that the geographical location does not affect the environmental or economic performance. This finding encourages considering both local and global environmental performances to have a broad environmental performance that may be used for any type of local and global environmental planning by decision-makers. The rest of the paper is organized as follows. 
Section 2 reviews the relative literature with the classical and environmental efficiency analysis of multi plants firms. Section 3 provides the primary models and material in the first subsection. In the second subsection, we develop environmental multi-plant DEA models dealing with undesirable outputs. The third subsection proposes a mixed, uniform, and non-uniform multi-plant DEA model for considering desirable and undesirable outputs simultaneously. Section 4 applies the proposed models for local and global classical and environmental efficiency analysis of Iranian power plants.

\section{Literature Review}

This method has extended for incorporating environmental issues into the efficiency analysis. Before that, the production function estimation operates for a single output case while DEA models can consider multiple outputs by [2]. A linear programming model was developed by [3] to analyze the efficiency of multi-plant firms in a DEA framework. An extension of the previous paper for the limited data was performed by [4]. They also used the multi-plant technology for efficiency analysis of multi-units [5]. Unlike the classical DEA models that were extended for dealing with pollution generating technology, the multi-plant DEA models cannot consider environmental issues. Analyzing the environmental performance of production units by DEA methods is growing, and this method has been intensively used for environmental efficiency analysis of different sectors in the last decades. A review for the application of DEA models in environmental and energy studies was done by [6]. A study for the UK's regional environmental efficiency using directional distance function DEA models was implemented by [7]. They investigate the link between regional environmental efficiency and economic growth and found a " $U$ " shape form for the link mentioned above. An investigation of the environmental efficiency of transportation sectors in 30 Chinese provinces was done by [8] between 2003 and 2012. They found the transportation sectors to be inefficient in most provinces. Another study by [9] used the DEA model to determine greenhouse gas emissions and carbon sequestration in small-scale maize production in Niger State, Nigeria. An environmental DEA model capable of handling zero and negative data was proposed by [10] and used for US industrial sectors' environmental efficiency analysis. An investigation of the corporate suitability of US industrial sectors was performed by [11] via an environmental efficiency analysis. They emphasized the role of the proposed DEA environmental assessment for corporate leaders in identifying how to invest in technology innovation to reduce undesirable output. A study on the role of the Central Government's policy was doen by [12] in China. They performed provincial level environmental analysis and concluded that though the Central Government's environmental policies fail to solve the inner contradiction between economic and environmental systems. In another study, the economic and environmental performance of wastewater treatment plants was investigated by [13] to find how it is potentially possible to reduce greenhouse gas emissions in the Valencia region on the Mediterranean coast of Spain. Classical DEA models were used by [14] for efficiency analysis and ranking of Iranian power plants at the country level. In another study by [15], classical DEA models were utilized for the environmental efficiency of ther$\mathrm{mal}$ and hydroelectric power plants in Iranian provinces. They found the average technical efficiency for the hydroelectric power plant in 2011 and 2010 are $62 \%$ and 53\%, respectively, and $82 \%$ and $77 \%$, for thermal power plants in 2011 and 2010, respectively. The technical and environmental efficiency of 16 selected thermal power plants in Iran was investigated by [16] during 2011-2015, using DEA. The technical efficiency of 26 thermal power plants in Iran was analyzed by [17] in the period of 2003-2008 using DEA and the Malmquist index. Iranian industrial sector emissions was studied by [18] using the input-output analysis during 1380-1390. They found that the production of final goods with the highest positive change is the most important factor affecting the increase of emissions. Another investigation was performed by [19] to measure the $\mathrm{CO}_{2}$ emission levels of Iranian provinces. They considered and analyzed the impact of population, urbanization, energy intensity, and per capita income on environmental degradation. The interactions between the Iranian 
industries' productive activities, the intensity of energy consumption by these activities, and the resulting environmental impacts (specifically $\mathrm{CO}_{2}$ emissions) were implemented by [20]. The current paper contributes to the literature in two ways. As a theoretical contribution, in this paper, we extend the multi-plant DEA model for dealing with undesirable outputs like pollution. We propose uniform and non-uniform multi-plant DEA models that consider the undesirable outputs. Moreover, other indices are also proposed for analyzing the local and global classical and environmental performance of production units. For the application side, we utilized the proposed model for the local and global classical and environmental efficiency analysis of 46 power plants in 21 provinces in Iran.

\section{Materials and Methods}

\subsection{Classical Multi-Plant Firm Production Technology}

Consider J multi-plant firms, numbered $j=1,2, \ldots, J$ and each firm has $K_{j}$ plants numbered $k=1,2, \ldots, K_{j}$. Assume each plant consumes $\mathrm{M}$ inputs and produces $\mathrm{N}$ desirable outputs. Let $x_{i k}^{j}$ be the $i$-the input $(1 \leq i \leq M), y_{r k}^{j}$ be the $r$-the desirable output $(1 \leq r \leq N)$ of plant $k$ at firm $j$. The general production technology can be represented by the output correspondence of $P^{j}: \mathbb{R}_{+}^{M} \rightarrow P^{j}(x) \subseteq \mathbb{R}_{+}^{N}$. Considering this setting and constant returns to scale for the production technology that consists of only the desirable output, we can consider the production set of $T_{C}^{j}=\left\{(x, y) \mid x \geq \sum_{k=1}^{K_{j}} \lambda_{k^{j}}^{j} x_{k^{\prime}}^{j} y \leq \sum_{k=1}^{K_{j}} \lambda_{k}^{j} y_{k^{\prime}}^{j} \lambda \geq 0\right\}$ for $j$-th firm. The following linear programming model can be found based on this production set for assessing the performance of the plant " 0 " of $j$-th firm.

$$
\begin{gathered}
\varphi_{L o}^{j}=\operatorname{Max} \varphi \\
\text { s.t } \\
\sum_{k=1}^{K_{j}} \lambda_{k}^{j} x_{i k}^{j} \leq x_{i o^{\prime}}^{j} \quad i=1,2, \ldots, m(1) \\
\sum_{k=1}^{K_{j}} \lambda_{k}^{j} y_{r k}^{j} \geq \varphi y_{r o}^{j}, \quad r=1,2, \ldots, s \\
\lambda_{k}^{j} \geq 0, \quad k=1,2, \ldots, K_{j}
\end{gathered}
$$

If we consider all plants operating in all production spaces, we have a broader production system, and plants may face more competitive environments. This setting is seen in the global industry, and thus, for assessing the performance plant " $O$ " considering all firms and associated plants, we may use the following linear programming:

$$
\begin{gathered}
\varphi_{G o}^{j}=\operatorname{Max} \varphi \\
\text { s.t } \\
\sum_{j=1}^{J} \sum_{k=1}^{K_{j}} \lambda_{k}^{j} x_{i k}^{j} \leq x_{i 0^{j}}^{j}, i=1,2, \ldots, m(2) \\
\sum_{j=1}^{J} \sum_{k=1}^{K_{j}} \lambda_{k}^{j} y_{r k}^{j} \geq \varphi y_{r o}^{j}, r=1,2, \ldots, s \\
\lambda_{k}^{j} \geq 0, \quad k=1,2, \ldots, K_{j}, j=1,2, \ldots, J .
\end{gathered}
$$

Please note that in the classical efficiency analysis, we consider only inputs and desirable outputs; thus, other measures like emission, etc., that can be considered as undesirable outputs are not considered in the above models and associated measures. The following subsection deals with undesirable outputs in the production process of multi-plant firms. 


\subsection{Multi-Plant Firm Environmental Production Technology}

Assume that each plant consumes not only $\mathrm{M}$ inputs and produces $\mathrm{N}$ desirable outputs but also P undesirable outputs. Let $x_{i k}^{j}$ be the $i$-the input $(1 \leq i \leq M), y_{r k}^{j}$ be the $r$-the desirable output $(1 \leq r \leq N)$, and $z_{h k}^{j}$ be the $h$-the undesirable output $(1 \leq h \leq P)$ of plant $k$ at firm $j$. We considered the general production technology that considers the undesirable outputs for the $j$-th plant by the output correspondence $P^{j}: \mathbb{R}_{+}^{M} \rightarrow P^{j}(x) \subseteq \mathbb{R}_{+}^{N+P}$. For dealing with both desirable and undesirable outputs, we considered the strong disposability for desirable output and the weak disposability for undesirable outputs proposed by [21] as follows. Strong disposability says if $y \in P^{j}(x)$ then $y^{\prime} \in P^{j}(x)$ for $y^{\prime} \leq y$ while weak disposability implies that $y \in P^{j}(x)$ then $\theta y \in P(x)$ for $0 \leq \theta \leq 1$. Considering $y$ and $z$ as desirable and undesirable outputs, we assumed that desirable outputs are strong disposal, and undesirable outputs are weak disposal in the context that if $(y, z) \in P^{j}(x)$, then $\left(y^{\prime}, z\right) \in P^{j}(x)$ for $y^{\prime} \leq y$.

Considering this and the constant returns to scale, we found the following output set for plant $j$ :

$$
T_{E L}^{j}=\left\{(x, y) \mid x \geq \sum_{k=1}^{K_{j}} \lambda_{k}^{j} x_{k^{\prime}}^{j} y \leq \sum_{k=1}^{K_{j}} \lambda_{k}^{j} y_{k^{\prime}}^{j} z=\sum_{k=1}^{K_{j}} \lambda_{k^{j}}^{j} z_{k^{\prime}}^{j} \lambda \geq 0\right\} .
$$

Considering this environmental production technology for the multi-plant firm, we may use the following linear programming model for assessing the performance of plant " $O$ " in the $j$-the firm.

$$
\begin{gathered}
\varphi_{E L o}^{j}=\operatorname{Max} \varphi \\
\text { s.t } \\
\sum_{k=1}^{K_{j}} \lambda_{k}^{j} x_{i k}^{j} \leq x_{i 0^{\prime}}^{j} \quad i=1,2, \ldots, m(3) \\
\sum_{k=1}^{K_{j}} \lambda_{k}^{j} y_{r k}^{j} \geq \varphi y_{r o}^{j}, \quad r=1,2, \ldots, s \\
\sum_{k=1}^{K_{j}} \lambda_{k}^{j} z_{h k}^{j}=z_{h o^{\prime}}^{j} \quad h=1,2, \ldots, P \\
\lambda_{k}^{j} \geq 0, \quad k=1,2, \ldots, K_{j}
\end{gathered}
$$

In contrast with the classical efficiency analysis and associated efficiency measure that was dealt in the previous section, in the environmental efficiency analysis of multi-plant firms, we considered any undesirable output that may be produced as a byproduct of the desired output.

Theorem 1. The environmental efficiency of an arbitrary plan in a firm is not greater than its classical efficiency measure.

The above theorem says if a production unit is efficient, then it is not necessarily environmentally efficient. In order to have acceptable environmental performance, production units need to take care of associated environmental issues that may not be considered in the classical efficiency analysis (Proof of Theorem 1 is available in Appendix A).

If we consider all firms and owned plants, we face a more competitive environment, and then we can use the following model for environmental efficiency of plants " $o$ ". In fact, 
in the global environmental analysis, we considered all plants' environmental performance belonging to all firms.

$$
\begin{gathered}
\varphi_{E G o}^{j}=\operatorname{Max} \varphi \\
\text { s.t } \\
\sum_{j=1}^{J} \sum_{k=1}^{K_{j}} \lambda_{k}^{j} x_{i k}^{j} \leq x_{i 0^{\prime}}^{j} i=1,2, \ldots, m(4) \\
\sum_{j=1}^{J} \sum_{k=1}^{K_{j}} \lambda_{k}^{j} y_{r k}^{j} \geq \varphi y_{r o}^{j}, \quad r=1,2, \ldots, s \\
\sum_{j=1}^{J} \sum_{k=1}^{K_{j}} \lambda_{k}^{j} z_{h k}^{j}=z_{h o^{\prime}}^{j} h=1,2, \ldots, P \\
\lambda_{k}^{j} \geq 0, \quad k=1,2, \ldots, K_{j}, j=1,2, \ldots, J
\end{gathered}
$$

Theorem 2. The classical efficiency of an arbitrary plant within its firm is not greater than its efficiency measure when considering all firms.

Corollary 1. The global classical environmental efficiency is greater than the local environmental efficiency, and we have the following relationship for the classical efficiency of $P_{0}^{j}$ and its classical and environmental efficiency $\varphi_{G o}^{j} \geq \varphi_{L o}^{j} \geq \varphi_{E L o}^{j}$.

Proof of Corollary 1. This can be concluded while considering Theorems 1 and 2 .

In order to measure the local-global efficiency measure of $P_{0}^{j}$ we proposed LocalGlobalindex $=\frac{\varphi_{G o}^{j}}{\varphi_{L o}^{j}}$ and for estimating the classical-environmental efficiency measure of $P_{o}^{j}$ we proposed Local-Environmental Index $=\frac{\varphi_{L o}^{j}}{\varphi_{E L o}^{j}}$. Regarding Corollary 1, we saw that Local-Global Index $=\frac{\varphi_{G o}^{j}}{\varphi_{L o}^{j}} \geq 1$. If this index is equal to unity, then it means that the evaluated plant could survive in the competitive global environment, since the local efficiency measure and the global efficiency measure are identical. Corollary 1 also concludes that Local-Environmental Efficiency $=\frac{\varphi_{L O}^{j}}{\varphi_{E L O}^{j}} \geq 1$. This index determines whether a plant is environmentally friendly or not. Unity value shows that the efficiency measure does not depend on the technology's environmental structure and is environmentally friendly if we assess it in a classical or environmental production technology context. Suppose this index is greater than unity, then the environmental issue matters and can affect its performance $P_{o}^{j}$.

Theorem 3. The global environmental efficiency of a plant is not greater than its local environmental efficiency.

Theorem 4. The global efficiency of a plant is not greater than its global environmental efficiency.

Corollary 2. The global classical environmental efficiency is not greater than the local environmental efficiency, and we have the following relationship for the classical efficiency of $P_{0}^{j}$ and its classical and environmental efficiency: $\varphi_{G o}^{j} \geq \varphi_{E G o}^{j} \geq \varphi_{E L o}^{j}$.

If we are interested in analyzing the global environmental performance, we can use the newly introduced index Global-Environmental Index $=\frac{\varphi_{G o}^{j}}{\varphi_{E G o}^{j}}$. Regarding Corollary 2, 
this index is also greater than or equal to unity $\frac{\varphi_{G o}^{j}}{\varphi_{E G o}^{j}} \geq 1$. If it is unity, then the environmental and classical efficiency of $P_{o}^{j}$ are equal globally. Otherwise, the environmental issue matters. We could see that a production unit's technically well performance does not necessarily imply an acceptable environmental performance. In other words, if a production unit is economically efficient, then we may not necessarily conclude that it is environmentally efficient too. For analyzing the environmental performance of $P_{o}^{j}$ the local and global production space, we introduced Environmetal Local-Global Index $=\frac{\varphi_{E G o}^{j}}{\varphi_{E L o}^{j}} \geq 1$. This index is also less than or equal to unity $\frac{\varphi_{E G o}^{j}}{\varphi_{E L o}^{j}} \geq 1$ and it indicates the situation of the environmental performance of $P_{o}^{j}$ in the local and global production. If it is equal to unity, then the environmental performance of $P_{o}^{j}$ is resistance globally. This means $P_{o}^{j}$ has a similar environmental performance both locally and globally. However, if it is greater than unity, then we face a sub-optimal local performance for $P_{o}^{j}$.

\subsection{Joint Scaling of Desirable and Undesirable Outputs}

Proposed models in the previous subsection only consider the desirable output and look for possible expansion of this type of output. However, we may take care of both desirable and undesirable outputs simultaneously. In previous models, we sought a possible expansion of desirable output while keeping undesirable output. But, there might be a possibility of areduction of undesirable outputs that are not considered in the previous models. Therefore, we proposed the following mixed model taking both desirable and undesirable factors into consideration.

$$
\begin{gathered}
\varphi_{U E L o}^{j}=\operatorname{Max} 1+\varphi \\
\text { s.t } \\
\sum_{k=1}^{K_{j}} \lambda_{k}^{j} x_{i k}^{j} \leq x_{i o^{\prime}}^{j} \quad i=1,2, \ldots, m(5) \\
\sum_{k=1}^{K_{j}} \lambda_{k}^{j} y_{r k}^{j} \geq(1+\varphi) y_{r o}^{j}, \quad r=1,2, \ldots, s \\
\sum_{k=1}^{K_{j}} \lambda_{k}^{j} z_{h k}^{j}=(1-\varphi) z_{h o^{\prime}}^{j} \quad h=1,2, \ldots, P \\
\lambda_{k}^{j} \geq 0, \quad k=1,2, \ldots, K_{j}
\end{gathered}
$$

The optimal value of the above model is less than or equal to zero. If it is zero, then the under-evaluation unit is efficient, otherwise it is inefficient.

Theorem 5. If a plant is locally mixed efficient then its local efficiency score is greater than or equal to the mixed local efficiency score.

An associated global model that simultaneous changes desirable and undesirable outputs can also be proposed by the following: 


$$
\begin{gathered}
\varphi_{\text {UEGo }}^{j}=\operatorname{Max} 1+\varphi \\
\text { s.t } \\
\sum_{j=1}^{J} \sum_{k=1}^{K_{j}} \lambda_{k}^{j} x_{i k}^{j} \leq x_{i 0^{\prime}}^{j}, i=1,2, \ldots, m(6) \\
\sum_{j=1}^{J} \sum_{k=1}^{K_{j}} \lambda_{k}^{j} y_{r k}^{j} \geq(1+\varphi) y_{r o}^{j}, \quad r=1,2, \ldots, s \\
\sum_{j=1}^{J} \sum_{k=1}^{K_{j}} \lambda_{k}^{j} z_{h k}^{j}=(1-\varphi) z_{h o}^{j} h=1,2, \ldots, P \\
\lambda_{k}^{j} \geq 0, \quad k=1,2, \ldots, K_{j}, j=1,2, \ldots, J .
\end{gathered}
$$

Theorem 6. If a plant is a locally mixed efficient plant, then its local efficiency score is greater than or equal to the mixed local efficiency score.

Proof of Theorem 6. It is similar to the proof of Theorem 5.

The previous subsection's proposed indices can be updated by the new mixed uniform measure of the model (5) and model (6). However, we cannot compare the efficiency measures using mixed models and peer models in the previous subsection, since the structure production technologies are different. Therefore, associated indices may be meaningless. However, we can still compare the local and global environmental performance of production units by the new mixed index of

$$
\text { Uniform Environmental Local-Global Index }=\frac{\varphi_{U E G o}^{j}}{\varphi_{U E L o}^{j}}
$$

Theorem 7. The global mixed efficiency measure of a production unit is greater than or equal to its local mixed efficiency measure.

Proof of Theorem 7. It is similar to the proof of Theorem 4.

Using Theorem 7, we then have

$$
\text { Uniform Environmental Local-Global Index }=\frac{\varphi_{U E G o}^{j}}{\varphi_{U E L o}^{j}} \geq 1 .
$$

The percentage of the desirable output expansion and the undesirable output reduction may not necessarily be equal; thus, we proposed the following model for the local and global environmental efficiency measurement of $P_{0}^{j}$. 


$$
\begin{gathered}
\varphi_{\text {NUELo }}^{j}=\operatorname{Max} 1+\varphi+\gamma \\
\text { s.t } \\
\sum_{k=1}^{K_{j}} \lambda_{k}^{j} x_{i k}^{j} \leq x_{i o^{\prime}}^{j} \quad i=1,2, \ldots, m(7) \\
\sum_{k=1}^{K_{j}} \lambda_{k}^{j} y_{r k}^{j} \geq(1+\varphi) y_{r o}^{j}, \quad r=1,2, \ldots, s \\
\sum_{k=1}^{K_{j}} \lambda_{k}^{j} z_{h k}^{j}=(1-\gamma) z_{h o^{\prime}}^{j}, h=1,2, \ldots, P \\
\lambda_{k}^{j} \geq 0, k=1,2, \ldots, K_{j} \varphi_{\text {NUEGo }}^{j}=\operatorname{Max} 1+\varphi+\gamma \\
s . t \\
\sum_{j=1}^{J} \sum_{k=1}^{K_{j}} \lambda_{k}^{j} x_{i k}^{j} \leq x_{i o^{\prime}}^{j}, i=1,2, \ldots, m(8) \\
\sum_{j=1}^{J} \sum_{k=1}^{K_{j}} \lambda_{k}^{j} y_{r k}^{j} \geq(1+\varphi) y_{r o}^{j}, \quad r=1,2, \ldots, s \\
\sum_{j=1}^{J} \sum_{k=1}^{K_{j}} \lambda_{k}^{j} z_{h k}^{j}=(1-\gamma) z_{h o^{\prime}}^{j} h=1,2, \ldots, P \\
\lambda_{k}^{j} \geq 0, k=1,2, \ldots, K_{j}, j=1,2, \ldots, J
\end{gathered}
$$

Theorem 8. The global mixed efficiency measure of a production unit is greater than or equal to its local mixed efficiency measure.

Proof of Theorem 8. It is similar to the proof of Theorem 7.

Using the model (7) and (8), we proposed the non-uniform environmental localglobal index as follows:Non-uniform Environmetal Local-Global Index $=\frac{\varphi_{N U E G o}^{j}}{\varphi_{N U E L o}^{j}}$ and using Theorem 8, we could see that Non-uniform Environmetal Local-Global Index = $\frac{\varphi_{N U E G O}^{j}}{\varphi^{j}} \geq 1$.

$\varphi_{\text {NUELo }}^{J}$ The local

( 7 ) and global model (8) consider the non-uniform scaling factor for desirable and undesirable output. In contrast, this factor is considered to be uniform in the local model (5) and global model (6). If we consider $\gamma=\varphi$ in the model (7) and model (8), then we get models (5) and (6), respectively. Therefore, we could consider model (5) and model (6) as a particular case of the model (7) and model (8), respectively.

Table 1 lists and summarizes the variables and parameters used in the current paper. 
Table 1. Decision variables and parameters.

\begin{tabular}{cc}
\hline Symbol & Description \\
\hline$x_{i k}^{j}$ & Parameter \\
$y_{r k}^{j}$ & The $i$-the input of plant $k$ at firm $j$ \\
$z_{h k}^{j}$ & The $r$-the desirable output of plant $k$ at firm $j$ \\
& The h-the undesirable output of plant $k$ at firm $j$ \\
\hline$\varphi_{k}$ & Decision variable \\
$\lambda_{k}^{j}$ & Poteintial output enlargement \\
\hline$P^{j}$ & The intensity variable of plant $k$ at firm $j$ \\
$T_{C}^{j}$ & Other symbols \\
$\varphi_{L o}^{j}$ & Output correspondence of firm $j$ \\
$\varphi_{G o}^{j}$ & Production technology of firm $j$ \\
$T_{E L}^{j}$ & Local efficiency measure of plant $o$ at firm $j$ \\
$\varphi_{L E o}^{j}$ & Global efficiency measure of plant $o$ at firm $j$ \\
$\varphi_{G E o}^{j}$ & Environmental local production technology of firm $j$ \\
$\varphi_{U L E o}^{j}$ & Local environmental efficiency measure of plant $o$ at firm $j$ \\
$\varphi_{U G E o}^{j}$ & Global environmental efficiency measure of plant $o$ at firm $j$ \\
$\varphi_{N U L E o}^{j}$ & Uniform local environmental efficiency measure of plant $o$ at firm $j$ \\
$\varphi_{N U G E o}^{j}$ & Non-uniform local environmental efficiency measure of plant $o$ at firm $j$ \\
\hline
\end{tabular}

\section{An Application for Local and Global Environmental Efficiency Analysis of Power Plants}

This section applies the proposed approach for environmental efficiency analysis of 46 power plants in 21 provinces of Iran. Provinces were assumed as plants at the local level, and the country was assumed as firm at the global level. Total assets were assumed as inputs, electricity production was taken as the desirable output, and pollution was assumed as an undesirable output. Table 2 reports the descriptive statistics of the data. We are willing to share our unnamed data set and codes for those who wish to replicate the results of this research.

Table 2. Statistical summary of data.

\begin{tabular}{|c|c|c|c|c|c|}
\hline Variable Type & Variable Name & Mean & Standard Error & Min & Max \\
\hline Input & Total assets & 760.6957 & 508.7195 & 42 & 2043 \\
\hline Output & $\begin{array}{l}\text { Electricity } \\
\text { production }\end{array}$ & 754,238 & $664,627.8$ & 2622.333 & $2,936,547$ \\
\hline Output & Pollution & 482,712 & $425,361.8$ & $1,879,390$ & 1678.293 \\
\hline
\end{tabular}

In the first analysis, we assessed the classical local and global performance of all power plants. The results are reported in Table 3.

We could observe some important facts confirming the proposed methodology and theorem. Most of the production units were found to be efficient at the local level, considering both classical and environmental productions. However, this was not the case at the global level. The classical global efficiency measures were found to be higher than or at least equal to the classical local efficiency measures. We had the same observation when we considered environmental technologies. This is a rational observation since the global environment is a more competitive space, and an under-evaluation unit needs to compete with more rivals at the global level. The same observation appears when we compared the environmental performance vs. the classical performance. This is also an expectable observation since if a production unit is technically efficient and not necessarily 
environmentally efficient, it does not matter at the local or global level. The local and global analysis is performed at the province and country-level, respectively. This shows that when considering the efficiency status of production units classical or environmental behavior may not reveal the whole picture of the production behavior. Thus, decision-makers are highly encouraged to consider the production behavior of DMUs at both local and global levels. Considering both classical and environmental production technology at the local and global levels, we reported the proposed indices in Table 4. Using this report, we analyzed and tracked the classical and environmental performance of production units at the local and global levels.

Table 3. Classical and environmental efficiency measures at the local and global level.

\begin{tabular}{|c|c|c|c|c|}
\hline Power Plant & $\begin{array}{c}\text { Local } \\
\text { Efficiency }\end{array}$ & $\begin{array}{l}\text { Local Environmental } \\
\text { Efficiency }\end{array}$ & $\begin{array}{l}\text { Global } \\
\text { Efficiency }\end{array}$ & $\begin{array}{c}\text { Global } \\
\text { Environmental } \\
\text { Efficiency }\end{array}$ \\
\hline P1 & 1 & 1 & 7.56080881 & 7.56080881 \\
\hline $\mathrm{P} 2$ & 1 & 1 & 8.0914273 & 8.0914273 \\
\hline P3 & 1.0548 & 1.0487 & 8.37519308 & 8.37519308 \\
\hline P4 & 1.4824 & 1.3254 & 15.3949782 & 15.3949782 \\
\hline P5 & 1 & 1 & 6.04726569 & 6.04726569 \\
\hline P6 & 1 & 1 & 5.92873151 & 5.92873151 \\
\hline P7 & 1.0025 & 1.0015 & 9.31173672 & 9.31173672 \\
\hline P8 & 1.0145 & 1.0112 & 222.98936 & 222.98936 \\
\hline P9 & 1 & 1 & 10.0435612 & 10.0435612 \\
\hline P10 & 1 & 1 & 1.01051666 & 1.01051666 \\
\hline P11 & 1 & 1 & 15.322035 & 15.322035 \\
\hline P12 & 1 & 1 & 5.60066461 & 5.60066461 \\
\hline P13 & 1 & 1 & 5.45235982 & 5.45235982 \\
\hline P14 & 1 & 1 & 22.0498452 & 22.0498452 \\
\hline P15 & 1 & 1 & 5.31678385 & 5.31678385 \\
\hline P16 & 1.0024 & 1 & 108.740439 & 108.740439 \\
\hline P17 & 1 & 1 & 6.63809458 & 6.63809458 \\
\hline P18 & 1 & 1 & 31.9781505 & 31.9781505 \\
\hline P19 & 1 & 1.0458 & 5.50775158 & 5.50775158 \\
\hline P20 & 1 & 1 & 7.57622863 & 7.57622863 \\
\hline P21 & 1 & 1 & 1 & 1 \\
\hline P22 & 1.0458 & 1.0415 & 7.2218846 & 7.2218846 \\
\hline $\mathrm{P} 23$ & 1 & 1 & 9.15474257 & 9.15474257 \\
\hline $\mathrm{P} 24$ & 1 & 1 & 10.0825616 & 10.0825616 \\
\hline P25 & 1 & 1 & 1.97976715 & 1 \\
\hline P26 & 1 & 1 & 1 & 1 \\
\hline P27 & 1 & 1 & 7.33669521 & 7.33669521 \\
\hline P28 & 1 & 1 & 6.2231639 & 6.2231639 \\
\hline P29 & 1 & 1 & 1.15865301 & 1.15865301 \\
\hline P30 & 1 & 1 & 6.78926893 & 6.78926893 \\
\hline P31 & 1 & 1 & 9.06070276 & 9.06070276 \\
\hline P32 & 1 & 1 & 1.76888648 & 1.76888648 \\
\hline P33 & 1 & 1 & 1 & 1 \\
\hline P34 & 1 & 1 & 3.15012452 & 3.15012452 \\
\hline P35 & 1 & 1 & 1.55292259 & 1.55292259 \\
\hline P36 & 1 & 1 & 4.25912395 & 4.25912395 \\
\hline P37 & 1 & 1 & 5.46666869 & 5.46666869 \\
\hline P38 & 1 & 1 & 2.79610979 & 2.79610979 \\
\hline P39 & 1 & 1 & 4.93834184 & 4.93834184 \\
\hline $\mathrm{P} 40$ & 1 & 1 & 3.59403477 & 3.59403477 \\
\hline P41 & 1 & 1 & 4.67331934 & 4.67331934 \\
\hline P42 & 1 & 1 & 2.49761552 & 2.49761552 \\
\hline $\mathrm{P} 43$ & 1 & 1 & 18.3410179 & 18.3410179 \\
\hline $\mathrm{P} 44$ & 1 & 1 & 4.00072678 & 4.00072678 \\
\hline $\mathrm{P} 45$ & 1 & 1 & 4.81755703 & 4.81755703 \\
\hline P46 & 1 & 1 & 7.67969877 & 7.67969877 \\
\hline
\end{tabular}


Table 4. Local-Global classical and environmental efficiency indices using a single scaling factor.

\begin{tabular}{|c|c|c|c|c|}
\hline Power Plant & $\begin{array}{l}\text { Local-Global } \\
\text { Index }\end{array}$ & $\begin{array}{c}\text { Environmental } \\
\text { Local-Global } \\
\text { Index }\end{array}$ & $\begin{array}{c}\text { Local } \\
\text { Environmental } \\
\text { Index }\end{array}$ & $\begin{array}{c}\text { Global } \\
\text { Environmental } \\
\text { Index }\end{array}$ \\
\hline P1 & 7.560809 & 7.560809 & 1 & 1 \\
\hline P2 & 8.091427 & 8.091427 & 1 & 1 \\
\hline P3 & 7.940077 & 7.986262 & 1.005817 & 1 \\
\hline $\mathrm{P} 4$ & 10.38517 & 11.61534 & 1.118455 & 1 \\
\hline P5 & 6.047266 & 6.047266 & 1 & 1 \\
\hline P6 & 5.928732 & 5.928732 & 1 & 1 \\
\hline P7 & 9.288515 & 9.29779 & 1.000999 & 1 \\
\hline P8 & 219.8022 & 220.5195 & 1.003263 & 1 \\
\hline P9 & 10.04356 & 10.04356 & 1 & 1 \\
\hline P10 & 1.010517 & 1.010517 & 1 & 1 \\
\hline P11 & 15.32203 & 15.32203 & 1 & 1 \\
\hline P12 & 5.600665 & 5.600665 & 1 & 1 \\
\hline P13 & 5.45236 & 5.45236 & 1 & 1 \\
\hline P14 & 22.04985 & 22.04985 & 1 & 1 \\
\hline P15 & 5.316784 & 5.316784 & 1 & 1 \\
\hline P16 & 108.4801 & 108.7404 & 1.0024 & 1 \\
\hline P17 & 6.638095 & 6.638095 & 1 & 1 \\
\hline P18 & 31.97815 & 31.97815 & 1 & 1 \\
\hline P19 & 5.507752 & 5.266544 & 0.956206 & 1 \\
\hline P20 & 7.576229 & 7.576229 & 1 & 1 \\
\hline P21 & 1 & 1 & 1.09558 & 1 \\
\hline P22 & 6.905608 & 6.934119 & 1.004129 & 1 \\
\hline $\mathrm{P} 23$ & 9.154743 & 9.154743 & 1 & 1 \\
\hline P24 & 10.08256 & 10.08256 & 1 & 1 \\
\hline P25 & 1.979767 & 1 & 1 & 1.979767 \\
\hline P26 & 1 & 1 & 1 & 1 \\
\hline $\mathrm{P} 27$ & 7.336695 & 7.336695 & 1 & 1 \\
\hline P28 & 6.223164 & 6.223164 & 1 & 1 \\
\hline P29 & 1.158653 & 1.158653 & 1 & 1 \\
\hline P30 & 6.789269 & 6.789269 & 1 & 1 \\
\hline P31 & 9.060703 & 9.060703 & 1 & 1 \\
\hline P32 & 1.768886 & 1.768886 & 1 & 1 \\
\hline P33 & 1 & 1 & 1 & 1 \\
\hline P34 & 3.150125 & 3.150125 & 1 & 1 \\
\hline P35 & 1.552923 & 1.552923 & 1 & 1 \\
\hline P36 & 4.259124 & 4.259124 & 1 & 1 \\
\hline P37 & 5.466669 & 5.466669 & 1 & 1 \\
\hline P38 & 2.79611 & 2.79611 & 1 & 1 \\
\hline P39 & 4.938342 & 4.938342 & 1 & 1 \\
\hline P40 & 3.594035 & 3.594035 & 1 & 1 \\
\hline P41 & 4.673319 & 4.673319 & 1 & 1 \\
\hline P42 & 2.497616 & 2.497616 & 1 & 1 \\
\hline $\mathrm{P} 43$ & 18.34102 & 18.34102 & 1 & 1 \\
\hline $\mathrm{P} 44$ & 4.000727 & 4.000727 & 1 & 1 \\
\hline P45 & 4.817557 & 4.817557 & 1 & 1 \\
\hline $\mathrm{P} 46$ & 7.679699 & 7.679699 & 1 & 1 \\
\hline
\end{tabular}

The local-global index shows only a few power plants that have a unity measure. Thus, we had just these power plants that have a resistant performance at the global level. P21, P26, and P33 are technically efficient both in the local and global environment. This result provides valuable information in the process of target setting for decision-makers. These power plants that are efficient at both local and global levels may be used for target setting instead of those that are efficient only at the local or global level. Next, we analyzed the environmental local-global index and again found a few power plants with independent 
environmental performance, regardless of the local or global level. We observed for P25, P26, and P33 that their environmental local-global index is equal.

In contrast with the previous analysis, we observed more production units with a unity measure of the global environmental index. This shows that the environmental performance was better managed at the local level, and policymakers need more attention towards managing the global environmental issue. Such information may be used in the process of environmental target setting. Another interesting observation is the similarity of the local-global index in the classical and environmental space. We observed that these indices are almost similar (second and third column). This shows that power plants' technical and environmental performance have the same pattern when considering the local and global levels. Therefore, the geographical location does not affect the technical and environmental performance of power plants. In the next analysis, we looked at the case from a different angle by the local and global environmental proposed indices. We are interested in measuring the environmental effects at the local and global levels. These indices are reported in the fourth column and fifth column of Table 4. We observed that at the local levels, we have a few power plants with a greater than equal value. This shows that there is a potential for environmental improvement for those power plants. However, when we looked at the global index, we observed only one power plant with such a situation. More deep investigation revealed that this power plant is owned by a border province with an old generation technology that struggles with providing gas and has used fuel for electricity production in some situations. In order to consider the desirable and undesirable output simultaneously, we used models (5) and model (6) for the local and global performance assessment in the subsequent analysis. The results are reported in Table 5.

We found less efficient power plants when we used the joint model, not only in classical production but also in environmental production. This was also an expectable observation; when we considered just desirable or undesirable output separately, we had an easier job reaching the efficient frontier rather than when considering both desirable and undesirable outputs simultaneously. For the efficiency measure of power plants using a mixed model, that efficient power plants using this model were also efficient using model 3 and model 4 at the local and global level. This could be found by comparing the second and third columns of Table 5 and peers in Table 3 . Note that we considered the scaling factor for both desirable and undesirable outputs in the mixed models of (5-6) while we had no scaling factor on undesirable output in the models (3-4). Using mixed environmental efficiency measures of power plants at the local and global level, we calculated the uniform environmental local-global index for all power plants reported in the sixth column of Table 5. We had only two power plants P26 and P34, which were resistant in the local and global environmental assessment. This emphasizes a more competitive space and a high potential for environmental improvement at the global level. Decision-makers and any environmental planning should consider this at the country level. Uniform factor analysis considers the simultaneous improvement of both desirable and desirable output; thus, we found more potential improvement, including desirable output enlargement and undesirable output reduction, in this analysis. However, the scaling factor of desirable and undesirable output may not be uniformly considered in the previous analysis. Thus, in the following analysis, we considered the non-uniform but joint scaling factor for the desirable and undesirable outputs. To this end, we used mixed models (7) and model (8) at the local environmental and global environmental levels, respectively. Table 6 lists the result of new efficiency measures and updated index regarding the local-global performance of power plants associated with new measures using models with non-uniform scaling factors.

The first observation was more discrimination power using models with the nonuniform scaling factor. Regarding the fact that the later model can be considered as a generalized model compared with models with a uniform scaling factor, we could expect this observation. More potential for environmental improvement was found using models with non-uniform scaling factors. We also saw that only the three power plants P21, P26, 
and P33 are environmentally resistant globally. Deeper analysis shows that these power plants are classically efficiency efficient in both the local and global space. More investigation reveals that these three power plants are classically efficient and environmentally efficient at both local and global levels. On the other hand, these are the only power plants that gained the unity value for all measures and associated indices. This fact shows that those power plants performing well in a classical and environmental manner can be the most favorable targets for other power plants at both local and global levels. However, the average local-global environmental index was about six, which emphasizes considering the local environmental performance and global environmental performance in any environmental planning at the local or country level. This emphasizes the classical and environmental efficiency at the local level and performs and indicates the global analysis of the classical and environmental efficiency status of production units.

Table 5. Local-Global classical and environmental efficiency indices using a uniform scaling factor.

\begin{tabular}{|c|c|c|c|}
\hline Power Plant & $\begin{array}{c}\text { Uniform Local } \\
\text { Environmental } \\
\text { Efficiency }\end{array}$ & $\begin{array}{l}\text { Uniform Global } \\
\text { Environmental } \\
\text { Efficiency }\end{array}$ & $\begin{array}{c}\text { Uniform } \\
\text { Environmental } \\
\text { Local-Global Index }\end{array}$ \\
\hline P1 & 1 & 1.944752099 & 1.944752099 \\
\hline P2 & 1.0354 & 1.971346572 & 1.971346572 \\
\hline P3 & 1.0584 & 1.968863777 & 1.8774328 \\
\hline $\mathrm{P} 4$ & 1.3354 & 1.99330027 & 1.503923548 \\
\hline P5 & 1 & 1.914830522 & 1.914830522 \\
\hline P6 & 1 & 1.936111985 & 1.936111985 \\
\hline P7 & 1.0015 & 1.96905577 & 1.966106611 \\
\hline P8 & 1.0112 & 1.99961275 & 1.977465141 \\
\hline P9 & 1 & 1.978610344 & 1.978610344 \\
\hline P10 & 1 & 1.005230826 & 1.005230826 \\
\hline P11 & 1 & 1.993344478 & 1.993344478 \\
\hline P12 & 1 & 1.908453623 & 1.908453623 \\
\hline P13 & 1 & 1.905882958 & 1.905882958 \\
\hline P14 & 1 & 1.99133302 & 1.99133302 \\
\hline P15 & 1 & 1.904868025 & 1.904868025 \\
\hline P16 & 1.0017 & 1.998726843 & 1.998726843 \\
\hline P17 & 1 & 1.935417814 & 1.935417814 \\
\hline P18 & 1 & 1.996998422 & 1.996998422 \\
\hline P19 & 1.0574 & 1.889884246 & 1.807118231 \\
\hline P20 & 1 & 1.912816684 & 1.912816684 \\
\hline P21 & 1 & 1 & 1 \\
\hline $\mathrm{P} 22$ & 1 & 1.953804471 & 1.875952444 \\
\hline $\mathrm{P} 23$ & 1 & 1.969964547 & 1.969964547 \\
\hline P24 & 1 & 1.980108822 & 1.980108822 \\
\hline P25 & 1 & 1.519158388 & 1.519158388 \\
\hline P26 & 1 & 1 & 1 \\
\hline P27 & 1 & 1.937004632 & 1.937004632 \\
\hline P28 & 1 & 1.888059933 & 1.888059933 \\
\hline P29 & 1 & 1.129664166 & 1.129664166 \\
\hline P30 & 1 & 1.950313132 & 1.950313132 \\
\hline P31 & 1 & 1.969786473 & 1.969786473 \\
\hline P32 & 1 & 1.504709418 & 1.504709418 \\
\hline P33 & 1 & 1 & 1 \\
\hline P34 & 1 & 1.603532748 & 1.603532748 \\
\hline P35 & 1 & 1.27041928 & 1.27041928 \\
\hline P36 & 1 & 1.84189491 & 1.84189491 \\
\hline P37 & 1 & 1.912792441 & 1.912792441 \\
\hline P38 & 1 & 1.72454979 & 1.72454979 \\
\hline P39 & 1 & 1.786074705 & 1.786074705 \\
\hline P40 & 1 & 1.663260315 & 1.663260315 \\
\hline P41 & 1 & 1.756371902 & 1.756371902 \\
\hline $\mathrm{P} 42$ & 1 & 1.793855307 & 1.793855307 \\
\hline $\mathrm{P} 43$ & 1 & 1.989310537 & 1.989310537 \\
\hline P44 & 1 & 1.916055549 & 1.916055549 \\
\hline P45 & 1 & 1.839949652 & 1.839949652 \\
\hline P46 & 1 & 1.959037015 & 1.959037015 \\
\hline
\end{tabular}


Table 6. Local-Global classical and environmental efficiency indices using a non-uniform scaling factor.

\begin{tabular}{|c|c|c|c|}
\hline Power Plant & $\begin{array}{c}\text { Non-Uniform Local } \\
\text { Environmental } \\
\text { Efficiency }\end{array}$ & $\begin{array}{l}\text { Non-Uniform } \\
\text { Global } \\
\text { Environmental } \\
\text { Efficiency }\end{array}$ & $\begin{array}{c}\text { Non-Uniform } \\
\text { Environmental } \\
\text { Local-Global Index }\end{array}$ \\
\hline P1 & 1 & 8.09142729 & 8.09142729 \\
\hline P2 & 1.43902307 & 8.37519308 & 5.82005474 \\
\hline P3 & 1.68100065 & 15.3949782 & 9.15822260 \\
\hline $\mathrm{P} 4$ & 1 & 6.21153570 & 6.21153570 \\
\hline P5 & 1 & 5.92873151 & 5.92873151 \\
\hline P6 & 1.21494955 & 9.37077363 & 7.71289112 \\
\hline P7 & 35.5037591 & 222.989359 & 6.28072535 \\
\hline P8 & 2.58316967 & 10.0933260 & 3.90734147 \\
\hline P9 & 1 & 1.01051666 & 1.01051666 \\
\hline P10 & 1.96369059 & 15.3220349 & 7.80267270 \\
\hline P11 & 1.00388961 & 5.77286465 & 5.75049743 \\
\hline P12 & 1 & 5.62912577 & 5.62912577 \\
\hline P13 & 1.48543471 & 22.0498452 & 14.8440352 \\
\hline P14 & 1 & 5.49180457 & 5.49180457 \\
\hline P15 & 10.1495961 & 108.740439 & 10.7137700 \\
\hline P16 & 1.39885265 & 6.71122533 & 4.7976642 \\
\hline P17 & 5.36906170 & 31.9781505 & 5.95600354 \\
\hline P18 & 1 & 5.72410083 & 5.72410083 \\
\hline P19 & 5.53539284 & 7.62722101 & 1.37790058 \\
\hline P20 & 1 & 1 & 1 \\
\hline P21 & 1 & 1 & 1 \\
\hline $\mathrm{P} 22$ & 1 & 7.221884598 & 7.221884598 \\
\hline P23 & 2.36310261 & 10.0839866 & 4.26726566 \\
\hline $\mathrm{P} 24$ & 2.02729392 & 2.08513153 & 1.02852946 \\
\hline P25 & 1 & 1 & 1 \\
\hline P26 & 1 & 7.46219151 & 7.46219151 \\
\hline P27 & 1 & 6.39031986 & 6.39031986 \\
\hline P28 & 1 & 1.70963893 & 1.70963893 \\
\hline P29 & 1 & 6.78926892 & 6.78926892 \\
\hline P30 & 1 & 9.06070276 & 9.06070276 \\
\hline P31 & 1 & 2.18082477 & 2.18082477 \\
\hline P32 & 1 & 1 & 1 \\
\hline P33 & 1 & 3.15012452 & 3.15012452 \\
\hline P34 & 1 & 1.55292259 & 1.55292259 \\
\hline P35 & 1 & 4.54565729 & 4.54565729 \\
\hline P36 & 1 & 5.60808255 & 5.60808255 \\
\hline P37 & 1 & 3.16396536 & 3.16396536 \\
\hline P38 & 1 & 4.93834183 & 4.93834183 \\
\hline P39 & 1 & 3.59403476 & 3.59403476 \\
\hline P40 & 1 & 4.67331934 & 4.67331934 \\
\hline P41 & 1 & 2.90542582 & 2.90542582 \\
\hline P42 & 1 & 18.3410178 & 18.3410178 \\
\hline P43 & 1 & 4.00072677 & 4.00072677 \\
\hline P44 & 1 & 4.81755702 & 4.81755702 \\
\hline P45 & 1 & 7.67969877 & 7.67969877 \\
\hline P46 & 1 & 8.09142729 & 8.09142729 \\
\hline
\end{tabular}

\section{Conclusions}

The current paper proposes new models for environmental assessment and localglobal analysis of pollution generating production units. In the application section, proposed models are used for Iranian power plants' local and global classical and environmental performance. However, the theoretical foundation and associated indices introduced in this paper can be used in any type of local-global analysis that is involved with environmental aspects. The proposed models put one step forward in contrast with classical 
efficiency analysis. It is highly recommended to utilize all developed indices for having a broad picture of classical and environmental performance in any performance analysis. One may perform well at the local level or may have an acceptable performance using classical models, but deeper analysis on the global level or considering environmental issues may provide better insight into the production. The current paper considers the production technology assuming convexity and constant returns to scale assumptions. Extending to other production technology types may not be a straightforward task, and we are still working on this. Investigating the production's scale effects is another important aim that can be achieved in a future research line.

Author Contributions: Conceptualization, M.G.; Data curation, M.G.; Formal analysis, F.T.-H.; Methodology, M.G.; Project administration, M.G.; Software, M.G.; Supervision, F.T.-H.; Validation, F.T.-H.; Writing—original draft, M.G.; Writing—review \& editing, F.T.-H. All authors have read and agreed to the published version of the manuscript.

Funding: Farhad Taghizadeh-Hesary acknowledges the financial support of the JSPS KAKENHI (2019-2020) Grant-in-Aid for Young Scientists No. 19K13742 and Grant-in-Aid for Excellent Young Researcher of the Ministry of Education of Japan (MEXT).

Institutional Review Board Statement: Not applicable.

Informed Consent Statement: Not applicable.

Data Availability Statement: Data are gathered from province and country sources. In the country source, we used the annual report of the energy ministry, and in the local level, we used power plants data of provinces.

Conflicts of Interest: The authors declare no conflict of interest.

\section{Appendix A}

Proof of Theorem 1. Consider plant " $o$ " of firm j denote it by $P_{o}^{j}$. The classical efficiency of this plant is gauged by the optimal value of model (1), that is, $\varphi_{L o}^{j}$ and its environmental efficiency measure is $\varphi_{E L o}^{j}$ that is the optimal value of model (3). Let $\left(\bar{\lambda}^{j}, \varphi_{E L o}^{j}\right)$ be the optimal solution of model (3); thus, we have

$$
\begin{gathered}
\sum_{k=1}^{K_{j}} \bar{\lambda}_{k}^{j} x_{i k}^{j} \leq x_{i o}^{j} i=1,2, \ldots, m \\
\sum_{k=1}^{K_{j}} \bar{\lambda}_{k}^{j} y_{r k}^{j} \geq \varphi_{E L o}^{j} y_{r o}^{j} r=1,2, \ldots, s \\
\sum_{k=1}^{K_{j}} \bar{\lambda}_{k}^{j} z_{h k}^{j}=y_{h o}^{j} h=1,2, \ldots, P \\
\bar{\lambda}_{k}^{j} \geq 0 k=1,2, \ldots, K_{j}
\end{gathered}
$$

Ignoring the third set of constraint from the above constraint set, we have

$$
\begin{gathered}
\sum_{k=1}^{K_{j}} \bar{\lambda}_{k}^{j} x_{i k}^{j} \leq x_{i o}^{j} i=1,2, \ldots, m \\
\sum_{k=1}^{K_{j}} \bar{\lambda}_{k}^{j} y_{r k}^{j} \geq \varphi_{E L o}^{j} y_{r o}^{j} r=1,2, \ldots, s
\end{gathered}
$$


$\lambda_{k}^{j} \geq 0 k=1,2, \ldots, K_{j}$ and this means that $\left(\bar{\lambda}^{j}, \varphi_{E L o}^{j}\right)$ is a feasible solution for the model (1) that implies $\varphi_{L o}^{j} \geq \varphi_{E L o^{\prime}}^{j}$ where $\varphi_{L o}^{j}$ is the optimal value of the classical model of (1), namely, the classical efficiency measure of the plant under evaluation.

Proof of Theorem 2. Consider $P_{o}^{j}$ then model (1) finds the classical efficiency of this plant, that is, $\varphi_{L o}^{j}$. Let $\left(\lambda^{j *}, \varphi_{L o}^{j}\right) \in \mathbb{R}_{+}^{K_{j}+1}$ be the optimal solution of model (1), then if satisfies associated constraint set of

$$
\begin{gathered}
\sum_{k=1}^{K_{j}} \lambda_{k}^{j *} x_{i k}^{j} \leq x_{i o}^{j} i=1,2, \ldots, m \\
\sum_{k=1}^{K_{j}} \lambda_{k}^{j *} y_{r k}^{j} \geq \varphi_{L o}^{j} y_{r o}^{j} r=1,2, \ldots, s \\
\lambda_{k}^{j *} \geq 0 k=1,2, \ldots, K_{j}
\end{gathered}
$$

Using this, we have a feasible solution for the model (2) that gauges the plant's efficiency under evaluation, considering all firm plants. Observe that $\left(\lambda^{j * *}, \varphi_{L o}^{j}\right) \in \mathbb{R}_{+}^{j=} K_{j}^{J+1}$ satisfies the following constraint set

$$
\begin{gathered}
\sum_{j=1}^{J} \sum_{k=1}^{K_{j}} \lambda_{k}^{j * *} x_{i k}^{j} \leq x_{i 0}^{j} i=1,2, \ldots, m \\
\sum_{j=1}^{J} \sum_{k=1}^{K_{j}} \lambda_{k}^{j * *} y_{r k}^{j} \geq \varphi_{L o}^{j} y_{r o}^{j} r=1,2, \ldots, s \\
\lambda_{k}^{j * *} \geq 0 k=1,2, \ldots, K_{j}, j=1,2, \ldots, J
\end{gathered}
$$

where $\lambda_{k}^{j * *}=\lambda_{k}^{j *}$ for the firm that owned plant " o" and $\lambda_{k}^{j * *}=0$ for other firms. This implies $\varphi_{G o}^{j} \geq \varphi_{L o}^{j}$, that is, the classical efficiency of $P_{o}^{j}$ within its firm is not greater than its efficiency measure when considering all firms.

Proof of Theorem 3. Mathematically, we can provide a similar argument to the proof of Theorem 2 to prove this theorem. However, we may also look at the problem from a production technology view. The production space for measuring the global environmental efficiency measure is larger than the production space for measuring the local environmental efficiency measure. This provides a broader production set when we consider the global production. Therefore we cannot expect lesser output efficiency measures in such production space compared with the local production space.

Proof of Theorem 4. Similar to the proof of Theorem 1, if we consider the model (4) that gauges the global environmental efficiency of $P_{o}^{j}$ then its optimal solution satisfies the following set of constraints.

$$
\begin{gathered}
\sum_{j=1}^{J} \sum_{k=1}^{K_{j}} \lambda_{k}^{j *} x_{i k}^{j} \leq x_{i o}^{j} i=1,2, \ldots, m \\
\sum_{j=1}^{J} \sum_{k=1}^{K_{j}} \lambda_{k}^{j *} y_{r k}^{j} \geq \varphi_{E G o}^{j *} y_{r o}^{j} r=1,2, \ldots, s
\end{gathered}
$$




$$
\begin{gathered}
\sum_{j=1}^{J} \sum_{k=1}^{K_{j}} \lambda_{k}^{j *} z_{h k}^{j}=y_{h o}^{j} h=1,2, \ldots, P \\
\lambda_{k}^{j *} \geq 0 k=1,2, \ldots, K_{j}, j=1,2, \ldots, J
\end{gathered}
$$

where $\left(\lambda_{k}^{j *}, \varphi_{E G 0}^{j *}\right), k=1,2, \ldots, K_{j}, j=1,2, \ldots, J$ is the optimal solution of model (4). If we consider the first and the second set of constraints in the above system of in-equality, then we reach the following

$$
\begin{gathered}
\sum_{j=1}^{J} \sum_{k=1}^{K_{j}} \lambda_{k}^{j *} x_{i k}^{j} \leq x_{i o}^{j} i=1,2, \ldots, m \\
\sum_{j=1}^{J} \sum_{k=1}^{K_{j}} \lambda_{k}^{j *} y_{r k}^{j} \geq \varphi_{E G o}^{j *} y_{r o}^{j} r=1,2, \ldots, s \\
\sum_{j=1}^{J} \sum_{k=1}^{K_{j}} \lambda_{k}^{j *} z_{h k}^{j}=y_{h o}^{j} h=1,2, \ldots, P \\
\lambda_{k}^{j *} \geq 0 k=1,2, \ldots, K_{j}, j=1,2, \ldots, J
\end{gathered}
$$

This implies that $\left(\lambda_{k}^{j *}, \varphi_{E G o}^{j *}\right)$ is a feasible solution of model (2) and therefore $\varphi_{G o}^{j *} \geq \theta_{E G 0^{\prime}}^{j *}$ that is, the global efficiency of a plant is not greater than its global environmental efficiency.

Proof of Theorem 5. Assume $P_{o}^{j}$ is efficient using the mixed model of (5), thus we have

$$
\begin{gathered}
\sum_{k=1}^{K_{j}} \lambda_{k}^{* j} x_{i k}^{j} \leq x_{i o}^{j} i=1,2, \ldots, m \\
\sum_{k=1}^{K_{j}} \lambda_{k}^{* j} y_{r k}^{j} \geq\left(1+\varphi^{*}\right) y_{r o}^{j}=y_{r o}^{j} r=1,2, \ldots, s \\
\sum_{k=1}^{K_{j}} \lambda_{k}^{* j} z_{h k}^{j}=\left(1-\varphi^{*}\right) z_{h o}^{j}=z_{h o}^{j} h=1,2, \ldots, P \\
\lambda_{k}^{* j} \geq 0 k=1,2, \ldots, K_{j}
\end{gathered}
$$

where, $\left(\lambda^{* j}, \varphi^{*}\right)=\left(\lambda^{* j}, \varphi_{U E L o}^{j}-1\right)$ is the optimal solution of mixed model (5). This implies $\left(\lambda^{* j}, \varphi^{*}\right)=\left(\lambda^{* j}, \varphi_{U E L o}^{j}\right)=\left(\lambda^{* j}, 1\right)$ is a feasible solution of model (3), that is,

$$
\begin{gathered}
\sum_{k=1}^{K_{j}} \lambda_{k}^{* j} x_{i k}^{j} \leq x_{i o}^{j} i=1,2, \ldots, m \\
\sum_{k=1}^{K_{j}} \lambda_{k}^{* j} y_{r k}^{j} \geq \varphi_{U E L o}^{j} y_{r o}^{j}=y_{r o}^{j} r=1,2, \ldots, s \\
\sum_{k=1}^{K_{j}} \lambda_{k}^{* j} z_{h k}^{j}=z_{h o}^{j} h=1,2, \ldots, P \\
\lambda_{k}^{* j} \geq 0 k=1,2, \ldots, K_{j}
\end{gathered}
$$

and this implies that $\varphi_{E L o}^{j} \geq \varphi_{U E L o}^{j}=1$. 


\section{References}

1. Charnes, A.; Cooper, W.; Rhodes, E. Measuring the efficiency of decision making units. Eur. J. Oper. Res. 1978, 2, 429-444. [CrossRef]

2. Farrell, M.J. The measurement of productive efficiency. J. R. Stat. Soc. Ser. A Gen. 1957, 120, 253-290. [CrossRef]

3. Färe, R.; Primont, D. Efficiency measures for multiplant firms. Oper. Res. Lett. 1984, 3, 257-260. [CrossRef]

4. Färe, R.; Primont, D. Efficiency measures for multiplant firms with limited data. In Measurement in Economics; Springer: Berlin/Heidelberg, Germany, 1988; pp. 177-186.

5. Färe, R.; Primont, D. Measuring the efficiency of multi-unit banking: An activity analysis approach. J. Bank. Financ. 1993, 17, 539-544. [CrossRef]

6. Zhou, P.; Ang, B.W.; Poh, K.-L. A survey of data envelopment analysis in energy and environmental studies. Eur. J. Oper. Res. 2008, 189, 1-18. [CrossRef]

7. Halkos, G.E.; Tzeremes, N.G. A conditional directional distance function approach for measuring regional environmental efficiency: Evidence from UK regions. Eur. J. Oper. Res. 2013, 227, 182-189. [CrossRef]

8. Song, X.; Hao, Y.; Zhu, X. Analysis of the environmental efficiency of the Chinese transportation sector using an undesirable output slacks-based measure data envelopment analysis model. Sustainability 2015, 7, 9187-9206. [CrossRef]

9. Sadiq, M.; Singh, I.P.; Suleiman, A.; Isah, M.A.; Umar, S.M.; Maude, A.M.; Lawal, A.; Sallawu, H. Application of Data Envelopment Analysis (DEA) to determine GHG emission and carbon sequestration in small-scale maize production in Niger State, Nigeria. Agric. Bionutr. Res. 2015, 1, 1-19.

10. Sueyoshi, T.; Yuan, Y. Comparison among US industrial sectors by DEA environmental assessment: Equipped with analytical capability to handle zero or negative in production factors. Energy Econ. 2015, 52, 69-86. [CrossRef]

11. Wang, D.; Li, S.; Sueyoshi, T. DEA environmental assessment on US Industrial sectors: Investment for improvement in operational and environmental performance to attain corporate sustainability. Energy Econ. 2014, 45, 254-267. [CrossRef]

12. Xia, Q.; Li, M.; Wu, H.; Lu, Z. Does the central government's environmental policy work. Evidence from the provincial-level environment efficiency in China. Sustainability 2016, 8, 1241. [CrossRef]

13. Molinos-Senante, M.; Hernández-Sancho, F.; Mocholí-Arce, M.; Sala-Garrido, R. Economic and environmental performance of wastewater treatment plants: Potential reductions in greenhouse gases emissions. Resour. Energy Econ. 2014, 38, 125-140. [CrossRef]

14. Pourkazemi, M.; Heydari, K. Data envelopment analysis and its application in evaluating the efficiency of power plants in Iran. Modarres Hum. Sci. 2002, 6, 35-54.

15. Javaheri, A.; Ostadzad, H. Estimating Efficiency of Thermal and Hydroelectric Power Plants in Iranian Provinces. Iran. J. Econ. Stud. 2014, 3, 19-42.

16. Emami meibodi, A.; Amadeh, H.; Amini, F. Evaluation of Technical and Environmental Efficiency of Selected Thermal Power Plants of Iran. Q. J. Energy Policy Plan. Res. 2017, 3, 33-67.

17. Emami Meibodi, A.; Afghah, M.; Rahmani Sefati, M.H. Measuring Technical Efficiency and Productivity in Steam, Gas and Compound Cycle Power Plants. Sci. J. Manag. Syst. 2009, 6, 79-103.

18. Jafari Samimi, A.; Najari, F. Evaluating the Contribution of Factors Affecting on Pollution Changes in Iran's Industrial Sector: Structural Decomposition Approach in the Input-Output Method. J. Environ. Sci. Stud. 2019, 3, 831-839.

19. Falahi, F.; Hekmati Farid, S. Determinants of $\mathrm{CO}_{2}$ Emissions in the Iranian Provinces (Panel Data Approach). Iran. Energy Econ. 2013, 2, 129-150. (In Persian)

20. Torabi, T.; Varesi, M. Studying the Environmental Pollution of Industries in Iran using an Input-Output Approach (Special Case of $\mathrm{CO}_{2}$ ). J. Environ. Sci. Technol. 2009, 11,77-92. (In Persian)

21. Färe, R.; Grosskopf, S.; Lovell, C.K.; Pasurka, C. Multilateral productivity comparisons when some outputs are undesirable: A nonparametric approach. Rev. Econ. Stat. 1989, 71, 90-98. [CrossRef] 